\title{
Self-Assembly of Semiflexible-Coil Chiral Block Copolymers under Various Segregation Strengths with Multiple Secondary Interactions
}

\author{
By Kai-Chieh Yang ${ }^{\dagger}$, Po-Ting Chiu ${ }^{\dagger}$, Hsiu-Wen Tsai ${ }^{\dagger}$, Rong-Ming Ho*广 \\ † Department of Chemical Engineering, National Tsing Hua University, Hsinchu 30013, \\ Taiwan
}

\section{Supporting information}

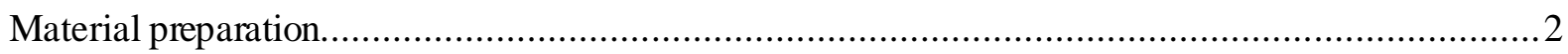

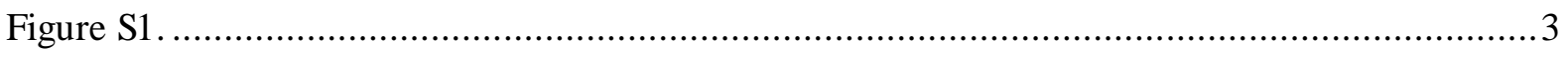

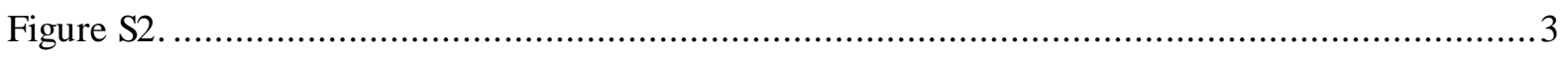

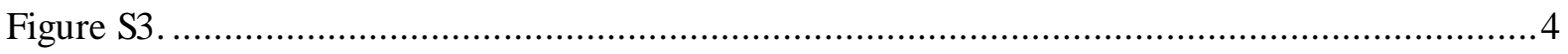

Crystallization Effect on Self-Assembled PS-PLLA.........................................................

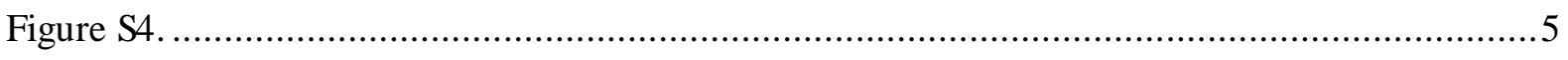

Scenario for the Formation of Undulation of the Lamellae...................................................... 6

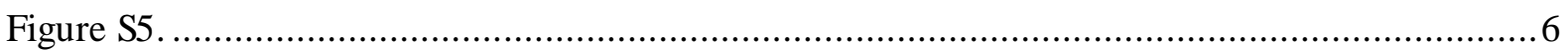

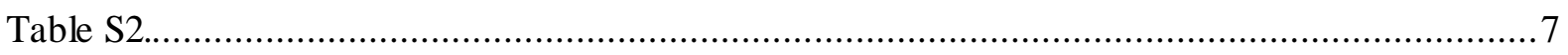

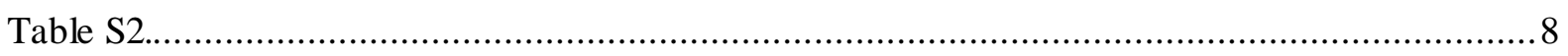

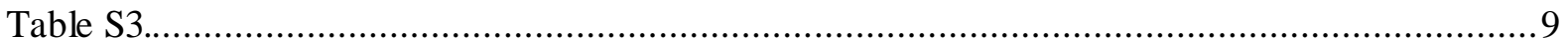




\section{Material preparation}

As illustrated in Figure S1, PS-PLLA samples were prepared by using a double-headed initiator for two-step polymerization with atom transfer radical (ATRP) for PS polymerization followed by ring-opening polymerization (ROP) of PLLA. ${ }^{1}$ The synthetic routes of PS-rich and PLLA-rich PS-PLLA are similar but different in the control of monomer conversion. Note that the copolymerization of PLLA from the macroinitiator of PS-OH will result in the solubility problem in the PS-selective solvent due to the increase of molecular weight for crystallizable PLLA, in particular for PLLA-rich PS-PLLA. The insolubility might cause the precipitation of the product, and thus the termination of the aimed copolymerization, resulting in a lower PLLA fraction in BCP. Moreover, the probability of the aimed copolymerization from the PS-OH macroinitiator might decrease as molecular weight increases, resulting in the homopolymerization of PLLA. Consequently, a synthetic route with low monomer conversion of L-lactide as low as 0.5 was carried out; With the combination of fractionation using acetonitrile as a solvent to remove unexpected products such as PLLA homopolymer, it is feasible to synthesize PLLA-rich PS-PLLA with controlled fractions of constituted blocks and also narrow polydispersity for self-assembly. As exemplified, $0.1 \mathrm{~g}$ PS-OH, $0.35 \mathrm{~g}$ L-lactide, 8 $\mathrm{mg} \mathrm{Sn}(\mathrm{Oct}) 2$, and $1.5 \mathrm{ml}$ dry toluene were added in the dry glass flask equipped with a magnetic stirrer in the glovebox for the synthesis of PS-PLLA with PLLA volume fraction 0.7.

Figure S2a shows the GPC curve of PS24-PLLA67 as a represented characterization for PLLA-rich PS-PLLA fractions in comparison with the PS-OH macroinitiator (Figure S2b); the number average molecular weight $(\mathrm{Mn})$ of the PS-OH was determined as approximately $24,000(\mathrm{~g} / \mathrm{mol})$ with polydispersity $(Đ)$ of 1.06 . After copolymerization, the polydispersity (Đ) of PS24-PLLA67 was determined as 1.30. Notably, the Mn for PS-PLLA cannot be determined by GPC due to the difference in excluding the volume of PLLA in THF as compared to the PS standard; therefore, the Mn for PS-PLLA was calculated from NMR spectroscopy. Figure S3 displays the ${ }^{1} \mathrm{H}$ NMR spectra of the PS24-PLLA67 at which PS-PLLA assignments are as listed as below: ${ }^{1} \mathrm{H} \mathrm{NMR}\left(500 \mathrm{MHz}, \mathrm{CDCl}_{3}\right): \delta=6.46-7.20(5 \mathrm{H}, \mathrm{ArH}), 5.12-5.16\left(\mathrm{q},{ }^{1} \mathrm{H}, \mathrm{CH}\left(\mathrm{CH}_{3}\right)\right.$ ), 1.82 (backbone, $\left.{ }^{1} \mathrm{H}, \mathrm{CH}\right), 1.58\left(\mathrm{~d}, 3 \mathrm{H}, \mathrm{CH}\left(\mathrm{CH}_{3}\right)\right.$ ), 1.40 (backbone, $2 \mathrm{H}, \mathrm{CH}_{2}$ ). Accordingly, the relative volume fractions of PS-PLLAs synthesized were determined by comparing the relative intensity of the respective ${ }^{1} \mathrm{H}$ resonances contributed by PLLA and PS based on the densities of PS and PLLA (1.04 and $1.25 \mathrm{~g} \mathrm{~cm}^{-3}$, respectively). The volume fraction of the PLLA in the PS24-PLLA67 is approximately 0.70. Accordingly, the total Mn for PS-PLLA was thus calculated to be approximately $91,000(\mathrm{~g} / \mathrm{mol})$. 


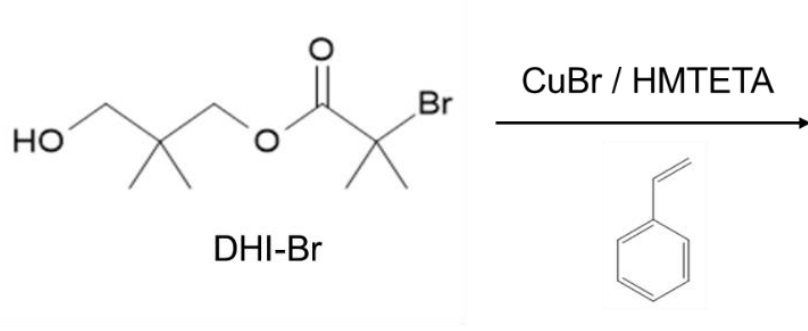<smiles>CC(C)(CO)COC(=O)C(C)(C)CC(C)(Br)c1ccccc1</smiles>
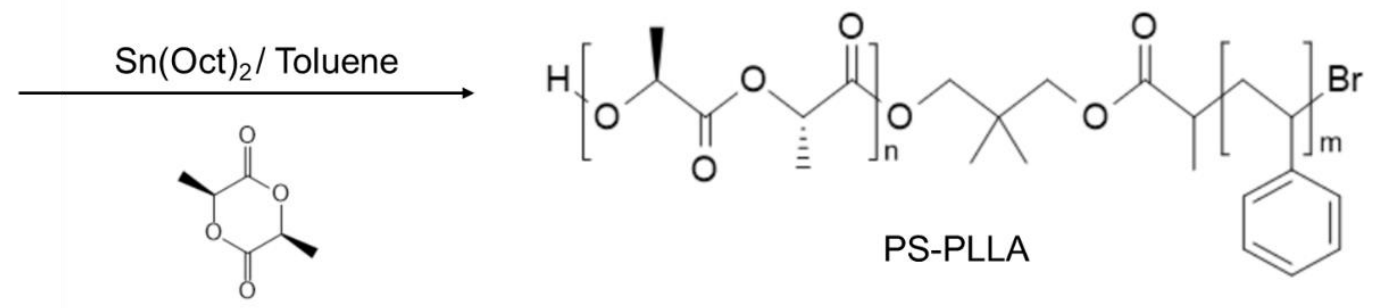

Figure S1. Synthetic routes of PLLA-rich PS-PLLA using two-step polymerization starting with ATRP of PS-OH followed by ROP of PLLA.

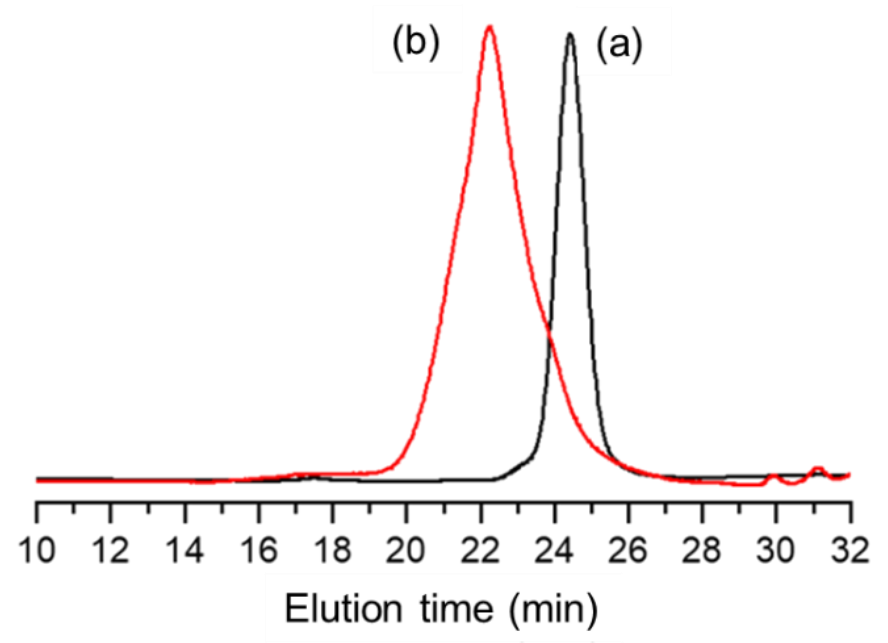

Figure S2. Comparison of GPC curves between (a) PS-OH and (b) PS24-PLLA67 as an exemplification of synthesized PLLA-rich PS-PLLA. 


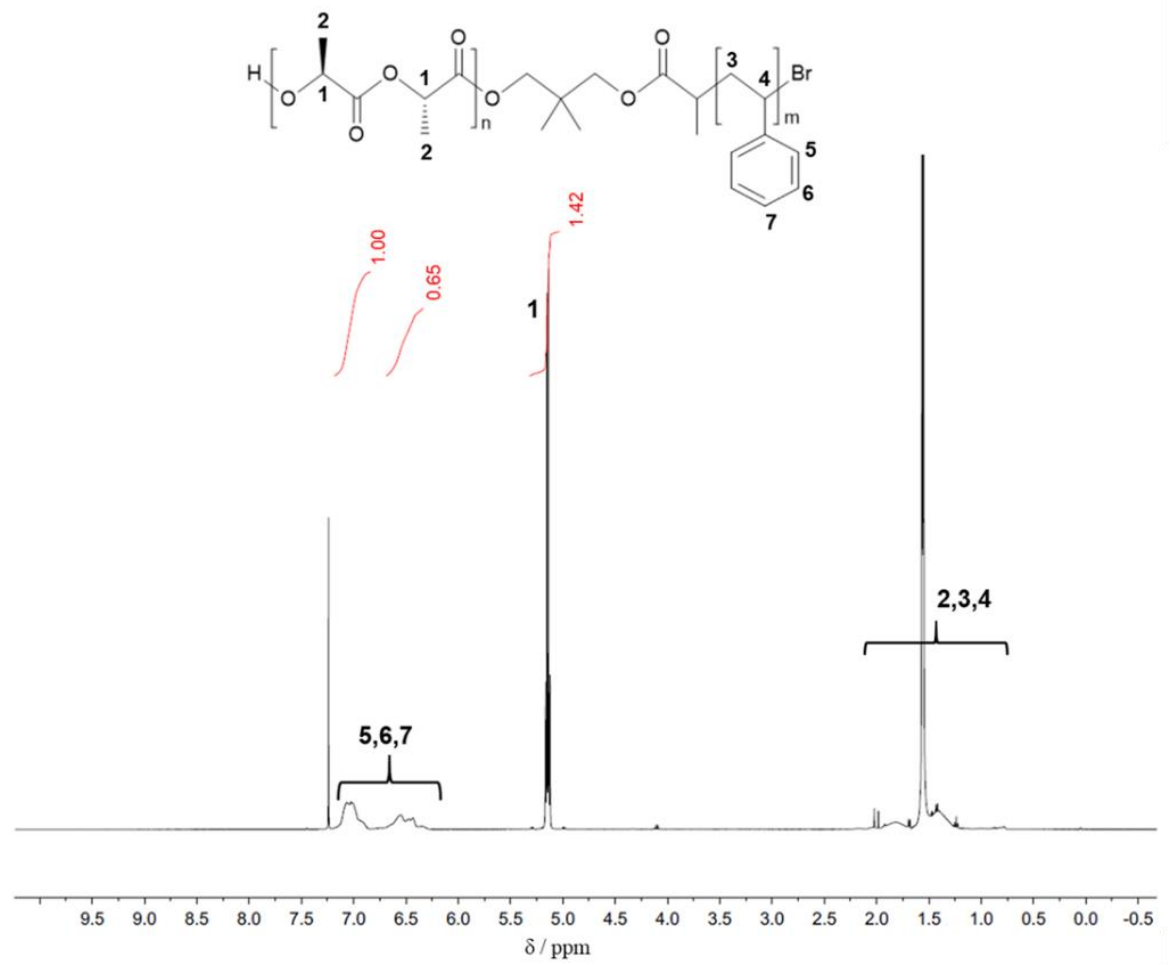

Figure S3. ${ }^{1} \mathrm{H}$ NMR spectrum of PS24-PLLA67 as an exemplification of characterization of the molecular weight and volume fraction of PLLA-rich PS-PLLA. The measurement was carried out using deuterated chloroform as a solvent at $25{ }^{\circ} \mathrm{C}$. 


\section{Crystallization Effect on Self-Assembled PS-PLLA}

To acquire a microphase-separated phase with the least interruption from crystallization event, solution-cast bulk samples were first thermally treated at $180{ }^{\circ} \mathrm{C}$ for 5 minutes to diminish the residual crystalline, followed by rapidly cooling to $140{ }^{\circ} \mathrm{C}$ for thermal annealing for 2 hours to improve the structural order. To examine the crystallization effect on selfassembled PS-PLLA, especially for PLLA-rich PS-PLLA, a stepwise WXRD measurement was carried out as exemplified by PS24-PLLA67 $\left(f_{\text {PLLA }^{v}}=0.70\right)$. The bulk sample was characterized by Bruker D2 Phaser diffractometer with $\mathrm{Cu} \mathrm{K} \alpha$ radiation $(\lambda=0.154 \mathrm{~nm})$ for $2 \theta$ scanning from $10^{\circ}$ to $30^{\circ}$ with a scanning rate of $2.0 \% \mathrm{~min}$.

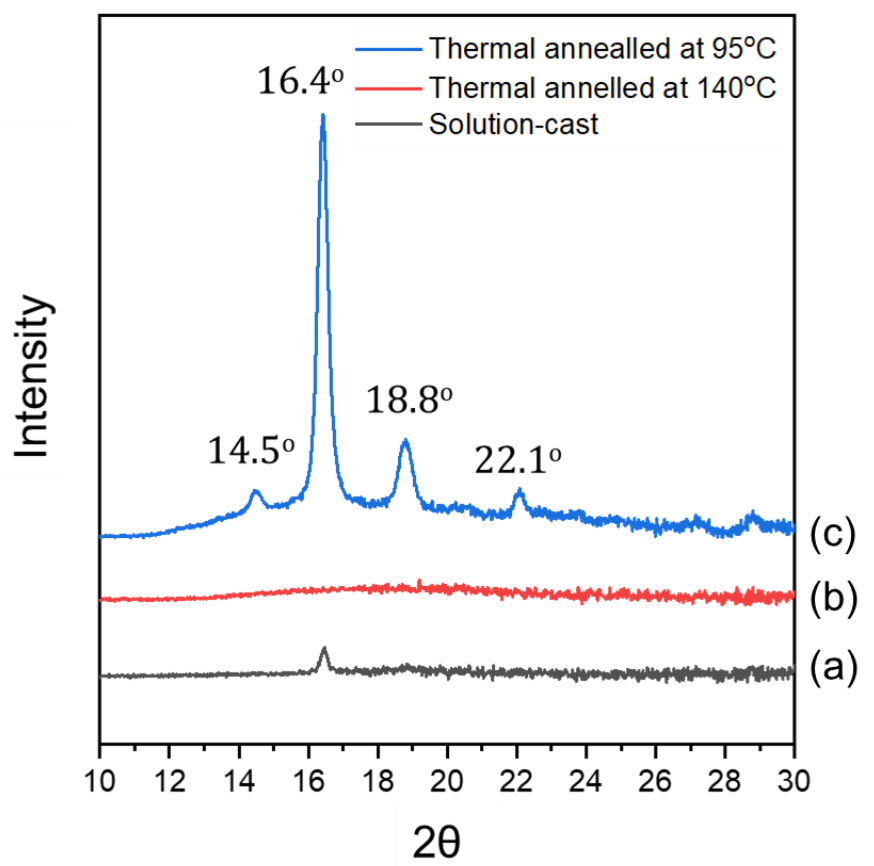

Figure S4. One-dimensional WAXD profiles of PS-PLLA after (a) solution casting; (b) solution casting followed by thermal annealing at $180{ }^{\circ} \mathrm{C}$ for 5 minutes after then rapidly cooling to $140{ }^{\circ} \mathrm{C}$ for $2 \mathrm{hr}$; (c) melt crystallization at $95^{\circ} \mathrm{C}$ for $2 \mathrm{hr}$. 


\section{Scenario for the Formation of Undulation of the Lamellae}

Undulated lamellae phase with the coexistence of out-of-phase and in-phase undulations can be observed from self-assembled PLLA-rich PS-PLLA in strong segregation strength region. We speculate that the undulation is attributed to the mutual effects of conformational asymmetry and chirality effects on the forming lamellae due to rod-rod interaction. As illustrated in Figure S5a, the out-of-phase undulation with small periodicity is originated from the conformational asymmetry effect on self-assembly, giving rise to interfacial curvatures toward the PLLA microd omain. Simultaneously, the in-phase periodic wave along the lamellar surface is attributed to the chirality effect on self-assembly (Figure S5b) which gives rise to the helical steric hindrance from the microphase-separated interface and the force field of interchain chiral interactions among self-assembled interdomains; therefore, twisting and shifting of lamellar microdomain can occur. Owing to the effects of conformational asymmetry, chirality and rod-rod interaction, a unique undulated lamellar phase is therefore formed from the self-assembly of PLLA-rich PS-PLLA.

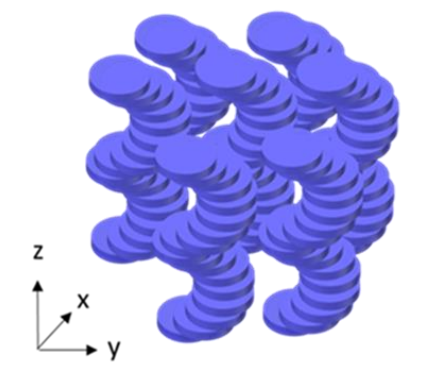

(a)
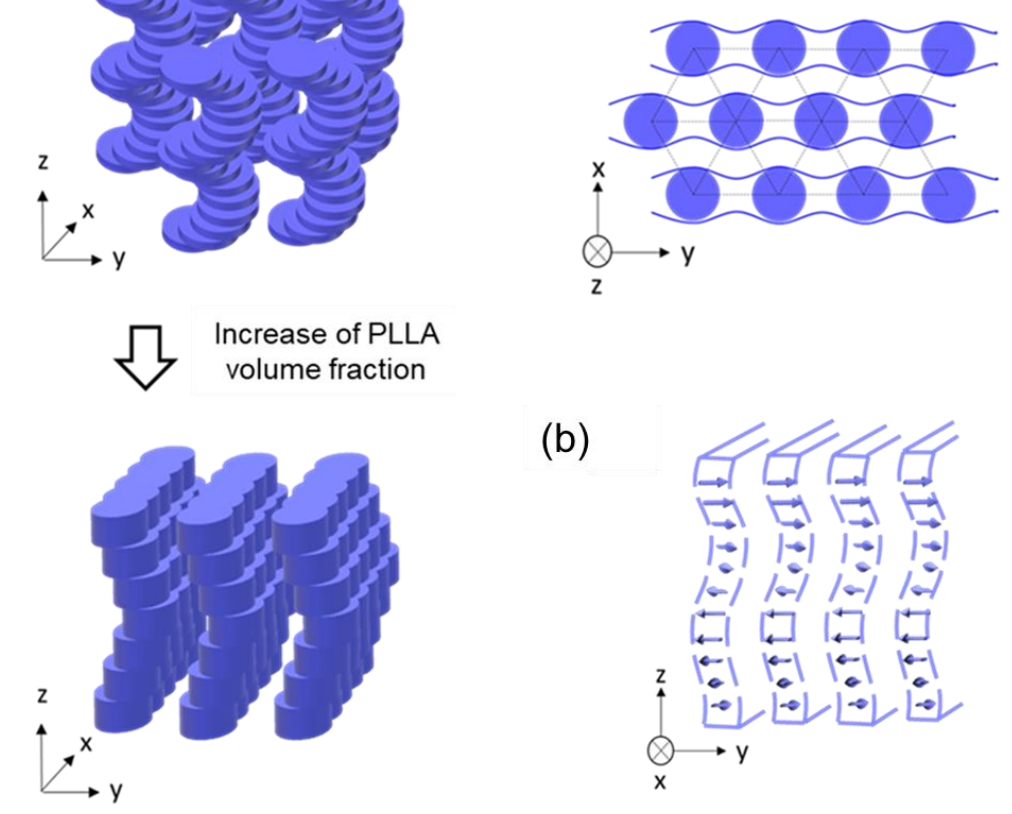

(b)

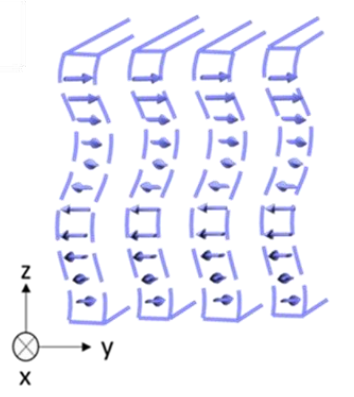

Figure S5. Illustration for lamellae-forming PLLA-rich PS-PLLA in the strong segregation region with out-of-phase undulation and in-phase undulation attributed to the effects of (a) conformational asymmetry and (b) chirality on self-assembly. 
Table S1. Characterization of weakly segregated PS-PLLA synthesized with PLLA volume fractions in-between 0.25 and 0.75 .

\begin{tabular}{|c|c|c|c|c|c|c|c|}
\hline \multirow[t]{2}{*}{ Sample $^{\mathrm{d}}$} & \multirow{2}{*}{$\begin{array}{c}\mathrm{M}_{\mathrm{n}}{ }^{\mathrm{a}} \\
\left(\mathrm{g} \mathrm{mol}^{-1}\right)\end{array}$} & \multirow[t]{2}{*}{$\bigoplus^{\mathrm{b}}$} & \multicolumn{2}{|c|}{$f^{v \mathrm{a}}$} & \multicolumn{2}{|c|}{$\mathrm{M}_{\mathrm{n}}^{\mathrm{a}}\left(\mathrm{g} \mathrm{mol}^{-1}\right)$} & \multirow{2}{*}{$\begin{array}{c}\chi \mathrm{N} \\
\left(140^{\circ} \mathrm{C}\right)\end{array}$} \\
\hline & & & PS & PLLA & PS & PLLA & \\
\hline PS100-PLLA47 & 14,700 & 1.21 & 0.71 & 0.29 & 10,000 & 4,700 & 21 \\
\hline PS90-PLLA46 & 13,600 & 1.26 & 0.69 & 0.31 & 9,000 & 4,600 & 19 \\
\hline PS90-PLLA49 & 13,900 & 1.25 & 0.68 & 0.32 & 9,000 & 4,900 & 20 \\
\hline PS85-PLLA48 ${ }^{\circ}$ & 13,300 & 1.09 & 0.67 & 0.33 & 8,500 & 4,800 & 19 \\
\hline PS90-PLLA58 ${ }^{\mathrm{c}}$ & 14,800 & 1.13 & 0.64 & 0.36 & 9,000 & 5,800 & 21 \\
\hline PS90-PLLA61 & 15,100 & 1.27 & 0.63 & 0.37 & 9,000 & 6,100 & 21 \\
\hline PS90-PLLA78 & 16,800 & 1.24 & 0.57 & 0.43 & 9,000 & 7,800 & 23 \\
\hline PS80-PLLA72 & 15,200 & 1.21 & 0.56 & 0.44 & 8,000 & 7,200 & 21 \\
\hline PS80-PLLA82 ${ }^{c}$ & 16,200 & 1.18 & 0.53 & 0.47 & 8,000 & 8,200 & 22 \\
\hline PS75-PLLA83 ${ }^{\circ}$ & 15,800 & 1.17 & 0.51 & 0.49 & 7,500 & 8,300 & 22 \\
\hline PS75-PLLA90 & 16,500 & 1.24 & 0.49 & 0.51 & 7,500 & 9,000 & 23 \\
\hline PS60-PLLA78 ${ }^{\mathrm{c}}$ & 13,800 & 1.30 & 0.47 & 0.53 & 6,000 & 7,800 & 19 \\
\hline
\end{tabular}

a determined by ${ }^{1} \mathrm{H}$ NMR based on, $\rho$ PS $=1.00 \mathrm{~g} \mathrm{~cm}^{-3}$, $\rho_{\text {PLLA }}=1.15 \mathrm{~g} \mathrm{~cm}^{-3}$ and a reference volume of $185 \AA^{3} .^{2-4}$

${ }^{\mathrm{b}}$ determined by GPC.

${ }^{\mathrm{c}}$ data reproduced from the previous paper: J. Am. Chem. Soc. 2009, 51, 18533.

d PSx-PLLAy, at which $\mathrm{x}$ and $\mathrm{y}$ represent the molecular weight (base $=100 \mathrm{~kg} / \mathrm{mol}$ ) 
Table S2. Characterization of intermediately segregated PS-PLLAs synthesized with PLLA volume fractions in-between 0.25 and 0.75 .

\begin{tabular}{|c|c|c|c|c|c|c|c|c|}
\hline \multirow[t]{2}{*}{ Sample $^{\mathrm{d}}$} & \multirow{2}{*}{$\begin{array}{c}\mathrm{M}_{\mathrm{n}}^{\mathrm{a}} \\
\left(\mathrm{g} \mathrm{mol}^{-1}\right)\end{array}$} & \multirow[t]{2}{*}{$\mathrm{Ð}^{\mathrm{b}}$} & \multicolumn{2}{|c|}{$f^{v \mathrm{a}}$} & \multicolumn{2}{|c|}{$\mathrm{M}_{\mathrm{n}}^{\mathrm{a}}\left(\mathrm{g} \mathrm{mol}^{-1}\right)$} & \multirow{2}{*}{$\begin{array}{c}\chi \mathrm{N} \\
\left(140^{\circ} \mathrm{C}\right)\end{array}$} & \multirow{2}{*}{$\begin{array}{c}d \text {-spacing } \\
(\mathrm{nm})\end{array}$} \\
\hline & & & PS & PLLA & PS & PLLA & & \\
\hline PS24-PLLA10 ${ }^{c}$ & 33,600 & 1.18 & 0.73 & 0.27 & 23,600 & 10,000 & 48 & NA \\
\hline PS21-PLLA11 ${ }^{c}$ & 31,400 & 1.21 & 0.69 & 0.31 & 20,700 & 10,700 & 44 & NA \\
\hline PS22-PLLA13 & 35,000 & 1.24 & 0.66 & 0.34 & 22,000 & 13,000 & 49 & NA \\
\hline PS18-PLLA12 ${ }^{c}$ & 29,600 & 1.26 & 0.64 & 0.36 & 18,000 & 11,600 & 41 & NA \\
\hline PS21-PLLA14 ${ }^{c}$ & 34,700 & 1.14 & 0.63 & 0.37 & 20,700 & 14,000 & 48 & NA \\
\hline PS12-PLLA8 & 20,500 & 1.25 & 0.62 & 0.38 & 12,000 & 8,500 & 29 & NA \\
\hline PS11-PLLA9 $^{c}$ & 20,000 & 1.17 & 0.58 & 0.42 & 10,900 & 9,100 & 28 & NA \\
\hline PS12-PLLA12 & 23,800 & 1.21 & 0.54 & 0.46 & 12,000 & 11,800 & 33 & NA \\
\hline PS14-PLLA16 ${ }^{c}$ & 29,300 & 1.20 & 0.50 & 0.50 & 13,600 & 15,700 & 40 & NA \\
\hline PS13-PLLA17 ${ }^{\circ}$ & 29,900 & 1.21 & 0.47 & 0.53 & 12,900 & 17,000 & 41 & NA \\
\hline PS8-PLLA12 & 19,000 & 1.23 & 0.43 & 0.57 & 7,500 & 11,500 & 26 & 26.5 \\
\hline PS8-PLLA14 & 21,600 & 1.22 & 0.38 & 0.62 & 7,500 & 14,100 & 29 & 27.3 \\
\hline PS6-PLLA11 & 17,200 & 1.22 & 0.37 & 0.63 & 5,800 & 11,400 & 23 & 25.4 \\
\hline PS8-PLLA16 & 23,500 & 1.24 & 0.35 & 0.65 & 7,500 & 16,000 & 32 & 28.6 \\
\hline PS6-PLLA14 & 20,000 & 1.26 & 0.32 & 0.68 & 5,800 & 14,200 & 27 & 25.4 \\
\hline PS8-PLLA22 & 29,600 & 1.24 & 0.28 & 0.72 & 7,500 & 22,100 & 39 & 31.6 \\
\hline
\end{tabular}

a determined by ${ }^{1} \mathrm{H}$ NMR based on, $\rho$ PS $=1.00 \mathrm{~g} \mathrm{~cm}^{-3}$, $\rho$ PLLA $=1.15 \mathrm{~g} \mathrm{~cm}^{-3}$ and a reference volume of $185 \AA^{3} \cdot{ }^{2-4}$

${ }^{b}$ determined by GPC.

${ }^{\mathrm{c}}$ data reproduced from the previous paper: J. Am. Chem. Soc. 2009, 51, 18533.

${ }^{\mathrm{d}}$ PSx-PLLAy, at which $\mathrm{x}$ and $\mathrm{y}$ represent the molecular weight (base=1000 kg/mol) 
Table S3. Characterization of strongly segregated PS-PLLAs synthesized with PLLA volume fractions in-between 0.25 and 0.75 .

\begin{tabular}{|c|c|c|c|c|c|c|c|c|}
\hline \multirow[t]{2}{*}{ Sample $^{\mathrm{d}}$} & \multirow{2}{*}{$\begin{array}{c}\mathrm{M}_{\mathrm{n}}^{\mathrm{a}} \\
\left(\mathrm{g} \mathrm{mol}^{-1}\right)\end{array}$} & \multirow[t]{2}{*}{$\mathrm{Ð}^{\mathrm{b}}$} & \multicolumn{2}{|c|}{$f^{v \mathrm{a}}$} & \multicolumn{2}{|c|}{$\mathrm{M}_{\mathrm{n}}^{\mathrm{a}}\left(\mathrm{g} \mathrm{mol}^{-1}\right)$} & \multirow{2}{*}{$\begin{array}{c}\chi N \\
\left(140^{\circ} \mathrm{C}\right) \\
\end{array}$} & \multirow{2}{*}{$\begin{array}{c}d \text {-spacing } \\
(\mathrm{nm})\end{array}$} \\
\hline & & & PS & PLLA & PS & PLLA & & \\
\hline PS38-PLLA16 ${ }^{\circ}$ & 54,000 & 1.21 & 0.73 & 0.27 & 38,000 & 16,000 & 76 & NA \\
\hline PS38-PLLA18 ${ }^{\circ}$ & 44,000 & 1.22 & 0.71 & 0.29 & 38,000 & 17,600 & 79 & $\mathrm{NA}$ \\
\hline PS34-PLLA19 & 53,200 & 1.14 & 0.67 & 0.33 & 34,000 & 19,200 & 75 & NA \\
\hline PS32-PLLA20 & 51,800 & 1.30 & 0.65 & 0.35 & 32,000 & 19,800 & 73 & 43.5 \\
\hline PS35-PLLA24 ${ }^{\mathrm{c}}$ & 58,700 & 1.11 & 0.63 & 0.37 & 35,000 & 23,700 & 82 & NA \\
\hline PS26-PLLA19 & 45,200 & 1.20 & 0.61 & 0.39 & 26,000 & 19,200 & 63 & 35.8 \\
\hline PS34-PLLA26 ${ }^{\mathrm{c}}$ & 60,100 & 1.13 & 0.60 & 0.40 & 34,000 & 26,100 & 84 & $\mathrm{NA}$ \\
\hline PS30-PLLA27 & 57,200 & 1.30 & 0.56 & 0.44 & 30,000 & 27,200 & 79 & 44.4 \\
\hline PS22-PLLA22 & 43,600 & 1.24 & 0.54 & 0.46 & 22,000 & 21,600 & 60 & 43.3 \\
\hline PS30-PLLA33 & 63,300 & 1.28 & 0.51 & 0.49 & 30,000 & 33,300 & 87 & 48.8 \\
\hline PS22-PLLA25 & 47,400 & 1.26 & 0.50 & 0.50 & 22,000 & 25,400 & 65 & 46.0 \\
\hline PS26-PLLA31 & 57,300 & 1.22 & 0.49 & 0.51 & 26,000 & 31,300 & 78 & 50.3 \\
\hline PS22-PLLA29 & 50,600 & 1.23 & 0.47 & 0.53 & 22,000 & 28,600 & 69 & 40.6 \\
\hline PS30-PLLA41 & 70,700 & 1.32 & 0.46 & 0.54 & 30,000 & 40,700 & 96 & 84.1 \\
\hline PS26-PLLA38 & 64,200 & 1.23 & 0.44 & 0.56 & 26,000 & 38,200 & 87 & 43.5 \\
\hline PS26-PLLA41 & 67,400 & 1.26 & 0.42 & 0.58 & 26,000 & 41,400 & 91 & 46.0 \\
\hline PS22-PLLA38 & 60,100 & 1.28 & 0.40 & 0.60 & 22,000 & 38,100 & 81 & 48.7 \\
\hline PS24-PLLA45 & 69,100 & 1.23 & 0.38 & 0.62 & 24,000 & 45,100 & 93 & 45.0 \\
\hline PS30-PLLA59 & 88,800 & 1.32 & 0.37 & 0.63 & 30,000 & 58,800 & 120 & 84.2 \\
\hline PS26-PLLA58 & 84,000 & 1.28 & 0.34 & 0.66 & 26,000 & 58,000 & 113 & 50.3 \\
\hline PS17-PLLA41 & 58,000 & 1.28 & 0.32 & 0.68 & 17,000 & 41,000 & 78 & 40.7 \\
\hline PS12-PLLA35 & 47,300 & 1.28 & 0.28 & 0.72 & 12,000 & 35,300 & 63 & 39.0 \\
\hline PS19-PLLA59 & 77,700 & 1.24 & 0.27 & 0.73 & 19,000 & 58,700 & 103 & 46.0 \\
\hline
\end{tabular}

a determined by ${ }^{1} \mathrm{HNMR}$ based on, $\rho$ PS $=1.00 \mathrm{~g} \mathrm{~cm}^{-3}$, $\rho$ PLLA $=1.15 \mathrm{~g} \mathrm{~cm}^{-3}$ and a reference volume of $185 \AA^{3}$. $^{2-4}$

${ }^{b}$ determined by GPC.

c data reproduced from the previous paper: J. Am. Chem. Soc. 2009, 51, 18533.

d PSx-PLLAy, at which $\mathrm{x}$ and y represent the molecular weight (base $=1000 \mathrm{~kg} / \mathrm{mol}$ ) 
1. Ho, R.-M.; Chiang, Y.-W.; Chen, C.-K.; Wang, H.-W.; Hasegawa, H.; Akasaka, S.; Thomas, E. L.; Burger, C.; Hsiao, B. S., Block Copolymers with a Twist. J. Am. Chem. Soc. 2009, 131, 18533-18542.

2. Hocker, H.; Blake, G. J.; Flory, P. J., Equation-of-state parameters for polystyrene. Trans. Faraday Soc., 1971, 67, 2251-2257.

3. Witzke, D. R.; Narayan, R.; Kolstad, J. J., Reversible kinetics and thermodynamics of the homopolymerization of L-lactide with 2-ethylhexanoic acid tin(II) salt. Macromolecules, 1997, 30, 7075-7085.

4. Zalusky, A. S.; O.-V. Roberto; H. W. Johanna; Hillmyer M. A., Ordered nanoporous polymers from polystyrene-polylactide block copolymers. J. Am. Chem. Soc. 2002, 124, 12761-12773. 